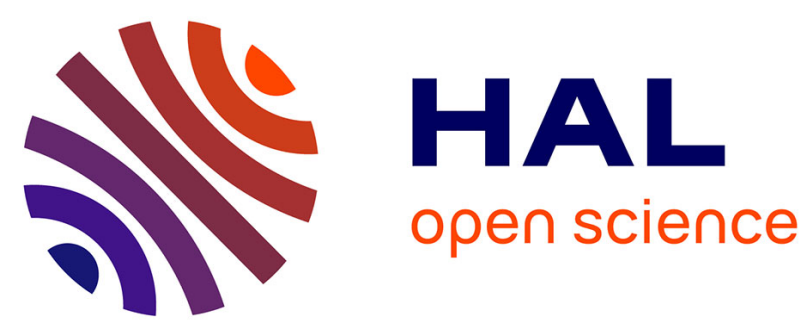

\title{
Combined Experimental and Theoretical Survey of the Gas-Phase Reactions of Serine-Ca2+ Adducts
}

\author{
Al Mokhtar Lamsabhi, Otilia Mó, Manuel Yáñez, Jean-Yves Salpin
}

\section{To cite this version:}

Al Mokhtar Lamsabhi, Otilia Mó, Manuel Yáñez, Jean-Yves Salpin. Combined Experimental and Theoretical Survey of the Gas-Phase Reactions of Serine-Ca2+ Adducts. Journal of Physical Chemistry A, 2019, 123 (29), pp.6241-6250. 10.1021/acs.jpca.9b03977 . hal-02263724

\section{HAL Id: hal-02263724 \\ https://hal.science/hal-02263724}

Submitted on 5 Aug 2019

HAL is a multi-disciplinary open access archive for the deposit and dissemination of scientific research documents, whether they are published or not. The documents may come from teaching and research institutions in France or abroad, or from public or private research centers.
L'archive ouverte pluridisciplinaire HAL, est destinée au dépôt et à la diffusion de documents scientifiques de niveau recherche, publiés ou non, émanant des établissements d'enseignement et de recherche français ou étrangers, des laboratoires publics ou privés. 


\title{
Combined Experimental and Theoretical Survey of the Gas-Phase Reactions of Serine-Ca ${ }^{2+}$ Adducts
}

\author{
Al Mohtar Lamsabhi ${ }^{a^{*}}$, Otilia Móa , Manuel Yáñez ${ }^{\mathrm{a}}$, Jean-Yves Salpin ${ }^{\mathrm{b}, c^{*}}$ \\ ${ }^{a}$ Departamento de Química, Módulo 13, Facultad de Ciencias and Institute of Advanced \\ Chemical Sciences (IadChem), Universidad Autónoma de Madrid, Campus de \\ Excelencia UAM-CSIC, Cantoblanco, 28049-Madrid, Spain. \\ b LAMBE, Univ Evry, CNRS, CEA, Université Paris-Saclay, F-91025, Evry- \\ Courcouronnes, France \\ ${ }^{\mathrm{c}}$ LAMBE, UCP, Université Paris-Seine, F-91025, Evry-Courcouronnes, France
}

\begin{abstract}
The association of $\mathrm{Ca}^{2+}$ to serine and the subsequent gas-phase unimolecular reactivity of the $[\mathrm{Ca}(\mathrm{Ser})]^{2+}(\mathrm{Ser}=$ Serine$)$ adduct was investigated throughout the use of tandem mass spectrometry techniques and B3LYP/6-311+G(3df,2p)//B3LYP/6-311+G(d,p) density functional theory calculations. In a first step, the structure and relative stability of all possible conformers of serine were obtained and analyzed, as well as the most stable $[\text { serine-Ca }]^{2+}$ adducts. For the analysis of the different potential energy surfaces associated with the gas-phase unimolecular reactivity of these adducts, only those that differ by less than $100 \mathrm{~kJ} \cdot \mathrm{mol}^{-1}$ from the global minimum were taken into account. In agreement with previous studies, the serine- $\mathrm{Ca}^{2+}$ global minimum corresponds to a charge-solvated structure in which $\mathrm{Ca}$ is tricoordinated to neutral serine. The major peaks observed in the nanoelectrospray-MS/MS spectrum of $[\mathrm{Ca}(\mathrm{Ser})]^{2+}$ adduct correspond to both, coulomb explosions, yielding either $\mathrm{CaOH}^{+}+\left[\mathrm{C}_{3}, \mathrm{H}_{6}, \mathrm{~N}, \mathrm{O}_{2}\right]^{+}$or $\left[\mathrm{C}_{2}, \mathrm{H}_{4}, \mathrm{O}, \mathrm{N}\right]^{+}+$ $\left[\mathrm{Ca}\left(\mathrm{C}, \mathrm{H}_{3}, \mathrm{O}_{2}\right)\right]^{+}$, and to the loss of neutrals, namely $\mathrm{CH}_{2} \mathrm{O}$, and $\mathrm{H}_{2} \mathrm{O}$. Our theoretical survey of the energy profile allow us to conclude that, although all the aforementioned fragmentation processes can have their origin at the global minimum, similar fragmentations involving low-lying conformers, both zwitterionic and non-zwitterionic compete and should be considered to account for the observed reactivity. We have also found that in some specific cases post-transition state dynamics similar to the ones described before in the literature for formamide- $\mathrm{Ca}^{2+}$ reactions, may also play a role.
\end{abstract}




\section{TABLE OF CONTENTS}

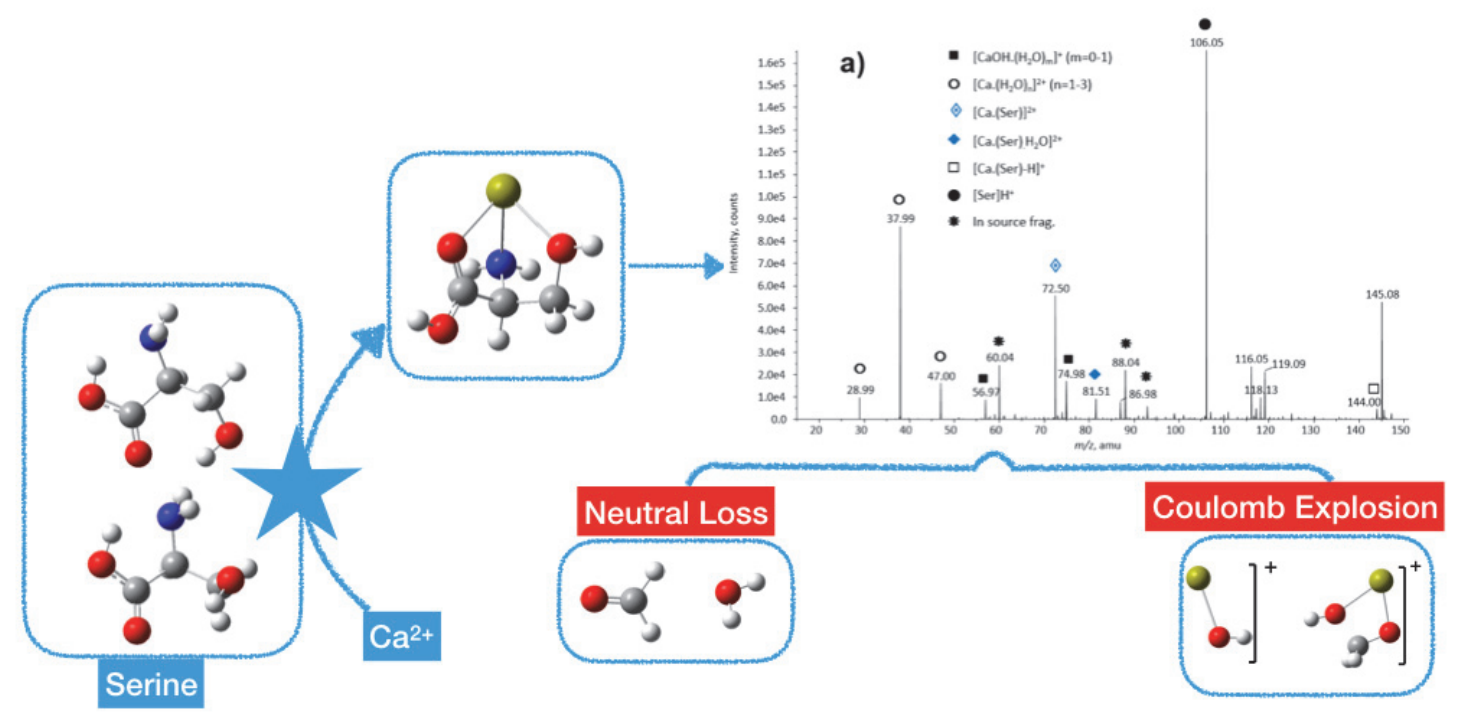

The major products observed in the gas-phase fragmentation reactions of [serine-Ca] ${ }^{2+}$ adducts correspond to both, coulomb explosions, yielding either $\mathrm{CaOH}^{+}+\left[\mathrm{C}_{3}, \mathrm{H}_{6}, \mathrm{~N}_{2} \mathrm{O}_{2}\right]^{+}$ or $\left[\mathrm{C}_{2}, \mathrm{H}_{4}, \mathrm{O}, \mathrm{N}\right]^{+}+\left[\mathrm{Ca}\left(\mathrm{C}, \mathrm{H}_{3}, \mathrm{O}_{2}\right)\right]^{+}$, and to the loss of neutrals, namely $\mathrm{CH}_{2} \mathrm{O}$, and $\mathrm{H}_{2} \mathrm{O}$

\section{INTRODUCTION}

Gas-phase ion chemistry ${ }^{1,2}$ is crucial to understand the intrinsic reactivity of a molecule in the absence of other factors, as solvation effects, that can deeply alter the reactivity patterns. However, a complete information on the intrinsic reactivity of a given compound cannot be usually achieved by just using experimental techniques, most of them in the realm of mass spectrometry, because the information obtained on the mechanism is scarce and fragmentary and, in this sense, the contribution of a parallel theoretical survey of the associated potential energy surface can be crucial to obtain a more complete picture of the whole phenomenon. ${ }^{3}$ In some cases, an even more realistic 
picture requires to include in the analysis the kinetic aspects through appropriate molecular dynamic formalism. ${ }^{4-6}$ However, the first step is unavoidable to have a good description of the potential energy surface and to check that it is compatible with the available experimental evidence.

The aim of this paper is to investigate, through the use of tandem mass spectrometry techniques and high-level DFT calculations, the gas-phase reactions between serine and $\mathrm{Ca}^{2+}$. Serine is a chiral aminoacid present in many proteins and $\mathrm{Ca}^{2+}$ is an alkaline-earth dication also systematically present in many biochemical environments. The study of serine reactivity is particularly interesting because of its high hydrophilicity since, together with threonine it is one of the two hydroxyl amino-acids, and is often found in the outer region of soluble proteins. $\mathrm{Ca}^{2+}$ is interesting not only because it is abundant in the physiological media, but also because of its low recombination energy. Its oxidative character $^{7}$ is much smaller than that of transition metal dications, and accordingly Ca-serine ${ }^{2+}$ dications can be experimentally detected and their reactivity analyzed. The obvious consequence is that two main fragmentations should be observed, those corresponding to coulomb explosions, where the products are two singly charged species, and the loss of neutral fragments accompanied by molecular dications lighter than the initial Ca-serine ${ }^{2+}$ species. In this respect it is interesting to mention that the dominant role of one of these reactive channels depends a lot on the nature of the neutral compound. A good example is provided by urea, thiourea, and selenourea. Whereas for urea the coulomb explosions are dominant, ${ }^{8}$ for thiourea ${ }^{9}$ and selenourea ${ }^{10}$ is the other way around and the reactivity is clearly dominated by the loss of neutrals. On top of that, whereas for urea some neutral loss, like that of ammonia, competes with the corresponding coulomb explosion producing $\mathrm{NH}_{4}+{ }^{+}$for selenourea the production of $\mathrm{NH}_{3}$ is almost negligible. ${ }^{10}$ Very interestingly, for glycine, that can be 
considered the result of replacing one of the amino groups of urea by a hydroxyl group, the reactivity patterns with $\mathrm{Ca}^{2+}$ changes completely, and whereas for urea the loss of neutral competes with the coulomb explosions, for glycine only coulomb explosions are concerned. We will see that with serine, where besides the amino-acid function we have a hydroxyl group, both kinds of reactions are observed. Our results also complement other previous studies on the interaction of $\mathrm{Ca}^{2+}$ and peptides. ${ }^{11}$ Indeed, the interaction of proteins with metals is a topic that attracted always high attention, ${ }^{12}$ and in particular on calcium binding proteins. ${ }^{13,14}$ Dealing with proteins it should be mentioned that the specific binding of $\mathrm{Ca}$ to proteins is so important in biochemistry that the denomination calciomics was proposed to designate these processes. ${ }^{15,16}$

\section{EXPERIMENTAL SECTION}

Both electrospray and MS/MS spectra were recorded in the positive-ion mode with a QqTOF hybrid instrument (QSTAR PULSARi/AB Sciex) equipped with a nanoelectrospray source. Several $\mu \mathrm{L}$ of aqueous mixtures of calcium chloride $\left(10^{-3} \mathrm{~mol}\right.$ $\left.\mathrm{L}^{-1}\right)$ and $\operatorname{Ser}\left(10^{-3} \mathrm{~mol} \mathrm{~L}^{-1}\right)$ were nanosprayed using borosilicate emitters (Proxeon) at a flowrate of several tens of $\mathrm{nL} \cdot \mathrm{min}^{-1}$. Sample ionization was achieved by applying a voltage of $900 \mathrm{~V}$ onto the nanospray tip, and by using the lowest possible nebulizing gas pressure (tens of millibars). The declustering potential (DP), which corresponds to the difference of potentials between the orifice plate and the skimmer (grounded), was varied from 0 to $30 \mathrm{~V}$ in order to determine the best conditions to observe the $\mathrm{Ca}^{2+} /$ serine doublycharged adduct. For better sensitivity, the collision gas $\left(\mathrm{N}_{2}\right)$ was present at all times to improve ion transmission by collisional focusing in both the Q0 (ion guide preceding Q1 and located just after the skimmer) and Q2 (collision cell) regions. 
For MS/MS spectra, the precursor ions of interest were mass selected using Q1, and allowed to collide with nitrogen as collision gas in the second quadrupole (Q2). The resulting fragment ions were finally characterized by the time-of-flight (TOF) mass analyzer after orthogonal injection. MS/MS spectra of the doubly charged ions were systematically recorded at various collision energies, adjusted by varying the difference between the potentials of Q0 and Q2 from $7 \mathrm{~V}$ to $14 \mathrm{~V}$. The amount of $\mathrm{N}_{2}$ introduced into Q2 was set to its minimum value, by setting the CAD parameter to 1 . However, given the actual pressure within Q2 (about $10 \mathrm{mTorr}^{17}$ ) and its size $(22 \mathrm{cms})$, at this pressure not only $\mathrm{N}_{2}$ molecules but also ions of interest (which have higher collision cross-sections) may undergo tens of collisions along their path through Q2, but also during their travel along Q0 and Q1, as N2 diffuses inside these quadrupoles. Consequently, MS/MS spectra are very likely obtained under multiple-collision regime, ${ }^{10,17}$ which further increases the amount of energy actually available.

Both calcium chloride and serine were purchased from Aldrich and used without further purification. All experiments were performed in Milli-Q purified water.

\section{COMPUTATIONAL DETAILS}

Taking into account that high-level ab initio calculations such as CCSD or $\mathrm{CCSD}(\mathrm{T})$ procedures are prohibitively expensive for systems of this size, we have decided to use density functional theory (DFT) approaches, which were shown to be a reasonably good and much cheaper alternative in a previous assessment in which the performance of a series of different theoretical procedures in describing the binding of $\mathrm{Ca}^{2+}$ to nitrogen and oxygen bases was carried out. ${ }^{18}$ Hence, all the calculation will be carried out using the B3LYP hybrid functional, ${ }^{19,20}$ as implemented in the Gaussian 09 suite of programs. ${ }^{21}$ The final energies were obtained ${ }^{22}$ at the B3LYP/6-311+G(3df,2p) 
level, on geometries optimized using a smaller basis set expansion, namely 6-311+G(d,p), which according to another recent assessment is suitable to obtain reliable geometries of $\mathrm{Ca}^{2+}$ adducts. ${ }^{23}$ The harmonic vibrational frequencies were evaluated also at the B3LYP/6-311+G(d,p) level and used to classify the stationary points as local minima or saddle points on the potential energy surface and to estimate the zero point vibrational energy (ZPVE) for each stationary point. The connectivity between the transition structures and the minima connected to them was confirmed through the use of the intrinsic reaction coordinate (IRC) procedure as implemented in Gaussian 09. ${ }^{21}$

Some preliminary molecular dynamics simulations were also carried out by using the extended Lagrangian molecular dynamics trajectory method that employs atomcentered basis functions and density matrix propagation (ADMP). ${ }^{24,25}$ This ADMP calculations were carried out using a B3LYP/6-311+G(d,p) formalism to obtain the density matrix, using an initial kinetic energy of 0.1 millihartree.

\section{RESULTS AND DISCUSSION}

\section{Mass Spectrometry Experiments}

The positive-ion nanospray spectrum of an equimolar aqueous mixture $\left(10^{-3} \mathrm{M}\right)$ of calcium chloride and Serine is presented in Figure 1a and is rather simple to interpret. This particular spectrum was obtained at $\mathrm{DP}=0 \mathrm{~V}$, which corresponds to the mildest source/interface conditions attainable. The base peak observed at $m / z 106.05$ corresponds to protonated serine, very likely obtained by proton transfer from the solvent due to the rather high gas-phase basicity of the amino acid.

Several series of calcium-containing species can be observed in significant abundances. The first one corresponds to hydrated calcium dications $\left[\mathrm{Ca}\left(\mathrm{H}_{2} \mathrm{O}\right)_{n}\right]^{2+}(\mathrm{n}=$ 1-3), detected at $m / z 28.99,37.99$ and 47.00 . Their intensity is generally significant at 
very low DP and is diagnostic of gentle source/interface conditions. Their intensity quickly drops as one increases the DP parameter. As a matter of fact $\left[\mathrm{Ca}\left(\mathrm{H}_{2} \mathrm{O}\right)_{n}\right]^{2+}$ ions easily dissociate according to two main competitive channels: ${ }^{26-28}$ i) loss of water molecules and charge separation process leading to either bare $(\mathrm{m} / \mathrm{z} 56.97)$ or solvated $(m / z 74.98)$ calcium hydroxide ions. The interaction of $\mathrm{Ca}^{2+}$ with the amino acid gives rise to two types of ions. The first one is the singly charged $[\mathrm{Ca}(\mathrm{Ser})-\mathrm{H}]^{+}$adduct $(\mathrm{m} / \mathrm{z}$ 144.00) detected in weak abundance. The second series corresponds to doubly-charged complexes of general formula $[\mathrm{Ca}(\mathrm{Ser})]^{2+}\left(\mathrm{m} / z\right.$ 72.50) and $\left[\mathrm{Ca}(\mathrm{Ser}) . \mathrm{H}_{2} \mathrm{O}\right]^{2+}(\mathrm{m} / z$ 81.51). Their abundance is maximum for $\mathrm{DP}=0 \mathrm{~V}$. Increasing the $\mathrm{DP}$ value results in the fast removal of the doubly-charged complexes by "in source" fragmentation processes leading notably to the species detected at $m / z 86.98$ and 88.04 (vide infra). Another in source fragmentation observed is the loss of $46 \mathrm{u}$ from protonated serine (a typical process for protonated amino acids) leading to the immonium ion $(\mathrm{m} / \mathrm{z} 60.04)$. The $\mathrm{m} / \mathrm{z} 88.04$ ion can also arise from dehydration of protonated serine. An additional ion is observed in significant abundance at $\mathrm{m} / z$ 145.08. It has already been observed for other $\mathrm{Ca}^{2+} /$ ligand systems that we studied in the past, and therefore does not result from an interaction with serine. Notably, the formation of $[\mathrm{Ca}(\mathrm{Ser})]^{+}$ion can be discarded as this ion should be observed at lower value $(\mathrm{m} / \mathrm{z}$ 145.01). Furthermore, examination of its isotopic distribution indicates a doubly charged ion, suggesting a possible interaction of $\mathrm{Ca}^{2+}$ with a known contaminant, presumably polypropylenglycol $(\mathrm{PPG}) .{ }^{29}$ The $\mathrm{PPG}\left[\left(\mathrm{C}_{3} \mathrm{H}_{6} \mathrm{O}\right)_{4}\right] \mathrm{H}_{2} \mathrm{O}$ species, interacting with $\mathrm{Ca}^{2+}$, would indeed result in a doubly-charged adduct theoretically detected at $\mathrm{m} / \mathrm{z} 145.07$ (monoisotopic peak), in agreement with the $\mathrm{m} / \mathrm{z}$ value observed.

The DP parameter was set to $0 \mathrm{~V}$ to record the MS/MS spectrum of the $[\mathrm{Ca}(\mathrm{Ser})]^{2+}$ adduct, and if necessary, slightly increased to promote in source/interface dissociation to 
generate its fragment ions in sufficient abundance for subsequent "MS/MS/MS like" experiments.

At $\mathrm{DP}=0 \mathrm{~V}$, the smallest potential difference between $\mathrm{Q} 2$ and Q0 leading to a recordable MS/MS spectrum for the $[\mathrm{Ca}(\mathrm{Ser})]^{2+}$ adduct was $7 \mathrm{~V}$. For this ion, the kinetic energy in the laboratory frame (Elab) was then scanned from 14 to $28 \mathrm{eV}\left(\mathrm{N}_{2}\right.$ being used as target gas). This corresponds to center-of-mass collision energies $\left(\mathrm{E}_{\mathrm{CM}}\right)$ ranging from 2.27 to $4.53 \mathrm{eV}$. The $\mathrm{CID}$ spectrum obtained at $\mathrm{E}_{\mathrm{lab}}=20 \mathrm{eV}$ is given in Figure $1 \mathrm{~b}$. The unimolecular reactivity of the $[\mathrm{Ca}(\mathrm{Ser})]^{2+}$ adduct is characterized by a combination of neutral losses and coulomb explosions, as already reported for cysteine. ${ }^{30}$ However, although only differing by a single atom within the side chain $\left(\mathrm{CH}_{2} \mathrm{OH}\right.$ vs $\left.\mathrm{CH}_{2} \mathrm{SH}\right)$, the unimolecular reactivity upon collision of the $[\mathrm{Ca}(\mathrm{Ser})]^{2+}$ and $[\mathrm{Ca}(\mathrm{Cys})]^{2+}$ adducts are markedly different. Examination of Figure $1 \mathrm{~b}$ shows that the neutral losses from the former correspond to elimination of water $\left(\mathrm{m} / z\right.$ 63.50) and $\mathrm{C}, \mathrm{H}_{2}, \mathrm{O}(\mathrm{m} / z$ 57.50), whereas deamination was clearly overwhelming with respect to loss of $\mathrm{H}_{2} \mathrm{~S}$ for the latter. ${ }^{30}$ The charge separation channels are also different. Thus, formation of the ammonium ion is not detected in presence of serine. Instead, two processes are observed, leading to $\mathrm{CaOH}^{+}$ $(m / z 56.97)$ and $\left[\mathrm{C}_{3}, \mathrm{H}_{6}, \mathrm{~N}, \mathrm{O}_{2}\right]^{+}\left(m / z\right.$ 88.04) in one hand, and to $\left[\mathrm{C}_{2}, \mathrm{H}_{4}, \mathrm{~N}, \mathrm{O}\right]^{+}(m / z 58.03)$ and $\left[\mathrm{Ca}, \mathrm{C}, \mathrm{H}_{3}, \mathrm{O}_{2}\right]^{+}(\mathrm{m} / z$ 86.98) on the other hand. Within a given pair, the fragment ions do not exhibit similar intensities. This can be explained by the secondary fragmentations, which have been studied by increasing the DP parameter, leading to fragmentation within the ESI interface and thus allowing MS/MS spectra of the primary fragment ions to be recorded. From this set of experiments the dissociation pattern displayed in scheme 1 could be established. For example, one can observe that the calcium hydroxide ion is formed from a primary process, but is also the quasi-unique fragment ion of the $m / z 86.98$ ion, as shown in Figure S1 of the Supporting Information. This particular process occurs 
readily as the $\mathrm{m} / \mathrm{z} 86.98$ is almost totally consumed at low collision energy, therefore accounting for the lower intensity of $m / z 86.98$ with respect to $m / z 58.03$, or the higher abundance of $\mathrm{CaOH}^{+}$as compared to $m / z 70.03$ and 88.04 (Figure 1b). Note that the latter ion mostly dissociates according to dehydration, generating the $\mathrm{m} / \mathrm{z} 70.03$ ion. Our experiments also show that the ion $\mathrm{m} / \mathrm{z} 63.50$ arising from dehydration is particularly reactive upon collision, notably exhibits four distinct neutral losses $\left(-\mathrm{H}_{2} \mathrm{O},-\mathrm{CO},-\mathrm{C}_{,} \mathrm{H}_{2}, \mathrm{O}\right.$ and $\mathrm{CO}_{2}$ ).

To summarize, the interaction of $\mathrm{Ca}^{2+}$ with serine promotes numerous fragment ions upon CID. This behavior is radically different from that observed in presence of different alkali metals. As a matter of fact, according to a series of threshold CID studies, the $\mathrm{M}^{+}$-serine adducts $(\mathrm{M}=\mathrm{Na}, \mathrm{K}, \mathrm{Rb}, \mathrm{Cs})$ react solely by loss of the intact serine when xenon is used as collision gas, ${ }^{31-33}$ suggesting a weaker interaction of the metal with the amino acid. For these four adducts, loss of intact serine is also observed upon Infrared Multiple Photon Ion Dissociation (IRMPD) activation. ${ }^{21}$ The interaction with $\mathrm{Li}^{+}$is much stronger, and consistently, the $[\mathrm{Li}-\mathrm{Ser}]^{+}$adduct exhibit additional fragmentation channels upon collision, such as loss of water, $\mathrm{C}, \mathrm{H}_{2}, \mathrm{O}$ and carbon dioxide. ${ }^{34}$ The two first processes are also observed with $\mathrm{Ca}^{2+}$ (vide supra). Finally, a combined experimental and theoretical study of the interaction of serine with two transition metals, namely cadmium and zinc, has been recently reported. ${ }^{35}$ The doubly-charged $\mathrm{M}^{2+}(\mathrm{Ser})$ adducts could not be generated in the gas phase, and IRMPD experiments were performed onto [ $\mathrm{Zn}(\mathrm{Ser}-$ $\left.\mathrm{H}) \mathrm{CH}_{3} \mathrm{CN}\right]^{+}$and $[\mathrm{CdCl}(\mathrm{Ser})]^{+}$ions. 


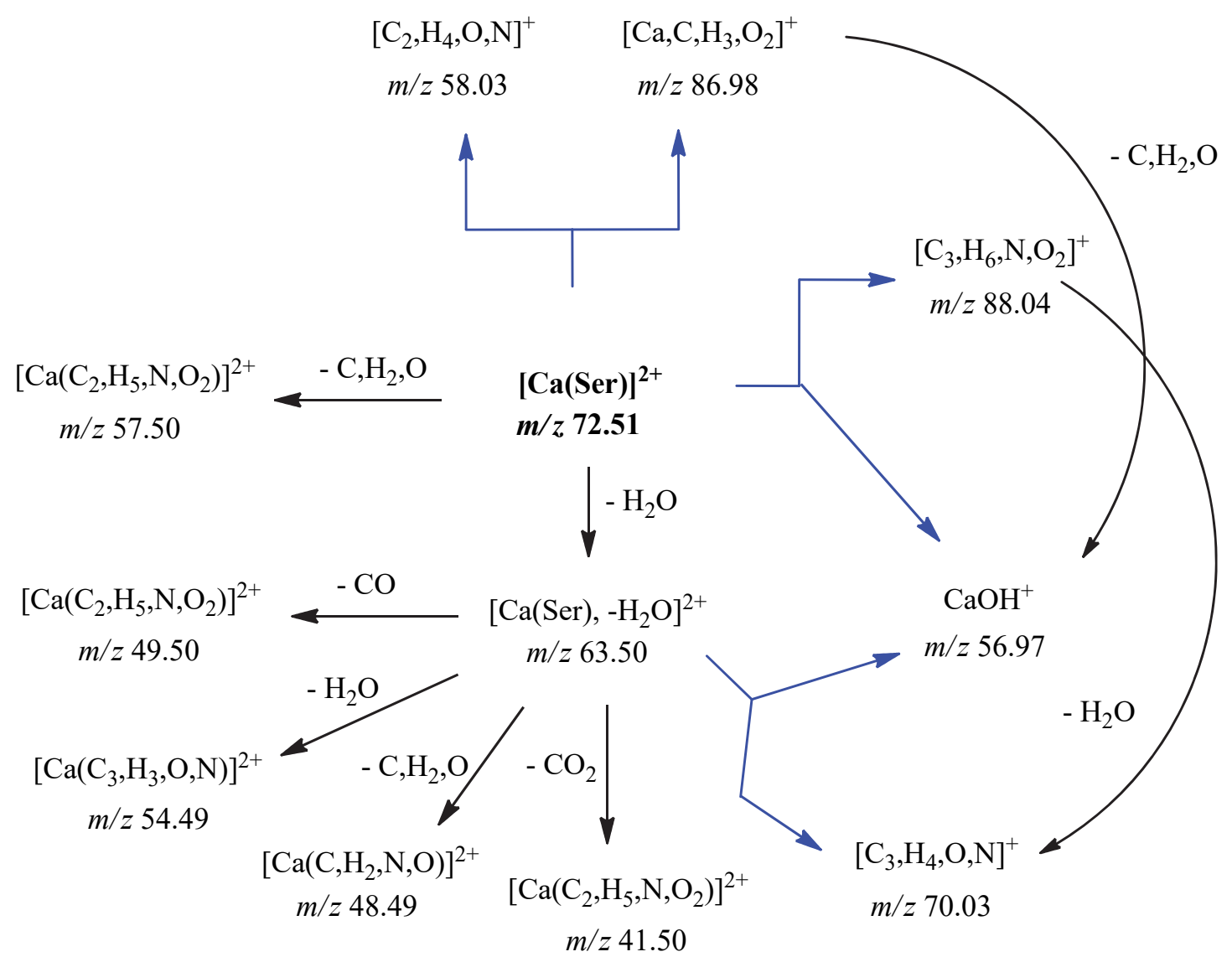

Scheme 1. Observed fragmentations of the $[\mathrm{Ca}(\mathrm{Ser})]^{2+}$ adduct upon CID. Black and blue arrows correspond to the loss of neutrals and coulomb explosions, respectively. 

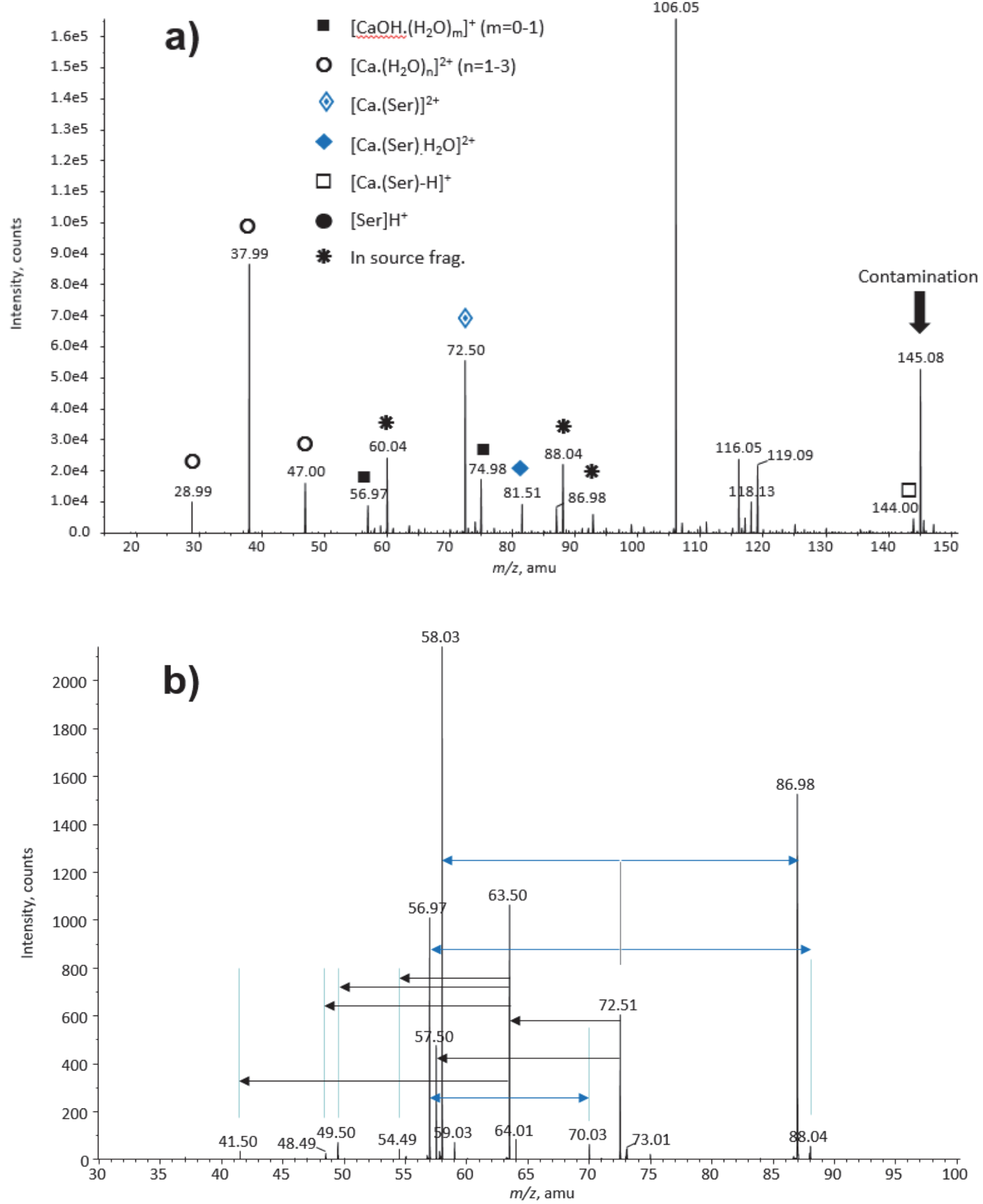

Figure 1. a) Nanospray spectrum of an equimolar aqueous mixture $\left(10^{-3} \mathrm{M}\right)$ of calcium chloride and serine recorded at $\mathrm{DP}=0 \mathrm{~V}$ and b) low-energy MS/MS spectrum of the $[\mathrm{Ca}(\mathrm{Ser})]^{2+}$ adduct $(\mathrm{m} / \mathrm{z} 72.51)$ recorded at a collision energy of $20 \mathrm{eV}$ (laboratory frame).

\section{Structures}


Molecular systems such as serine are very rich from the conformational point of view. Although in previous theoretical studies on the infrared spectra of glycine-, cysteine- and serine- $\mathrm{Ca}^{2+}$, the most stable conformers of serine- $\mathrm{Ca}^{2+}$ adducts were reported, ${ }^{22,36}$ a complete characterization of the potential energy surface associated with the gas-phase reactivity between serine and $\mathrm{Ca}^{2+}$ requires to fully investigate the relative stability of the different conformers of the neutral compound and of their adducts with $\mathrm{Ca}^{2+}$, because under CID conditions endothermic reactions and dissociations may be possible and because during the ESI process it cannot be excluded that some high-energy conformers may be formed and kinetically trapped. In our B3LYP/6$311+\mathrm{G}(3 \mathrm{df}, 2 \mathrm{p}) / / \mathrm{B} 3 \mathrm{LYP} / 6-311+\mathrm{G}(\mathrm{d}, \mathrm{p})$ survey of serine conformers, we have characterized a total of 41 local minima, whose relative energies are summarized in Table S1 of the Supporting Information. A Boltzmann distribution of these conformers, obtained at room temperature $(298.15 \mathrm{~K})$, is shown in Figure S2 of the Supporting Information and allowed us selecting the six conformers (see Figure 2) out of a total of 41 conformers investigated whose abundance is larger than $3 \%$ and which are going to be the ones retained for our analysis of the serine- $\mathrm{Ca}^{2+}$ reactions. The structures shown in Figure 2 were previously reported by G. Bouchoux ${ }^{37}$ as the most stable conformers obtained at the G4 level of theory, though the relative order was not strictly the same because we are focusing our attention in conformers which differ in a very small amount of energy $\left(6 \mathrm{~kJ} \cdot \mathrm{mol}^{-1}\right)$. 


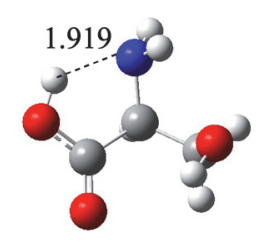

0.4

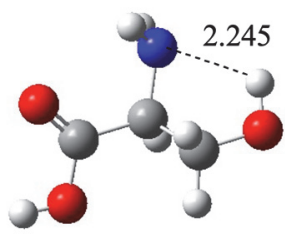

0.0

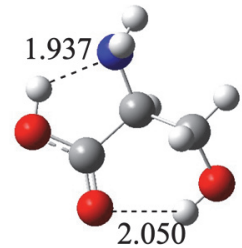

2.1

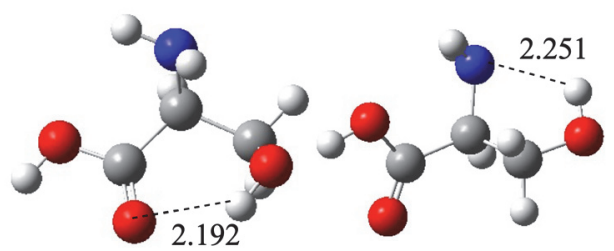

5.9

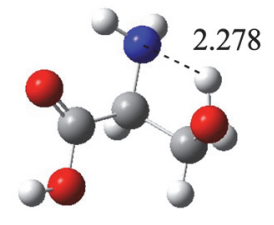

3.0

6.9

Figure 2. B3LYP/6-311+G(d,p) optimized geometries of the most stable conformers of serine. Relative enthalpies (in $\mathrm{kJ} \cdot \mathrm{mol}^{-1}$ ) calculated at $298.15 \mathrm{~K}$ are given. Dashed lines show the intramolecular hydrogen bonds stabilizing these systems (See the corresponding molecular graphs in Figure S3 of the Supporting Information). Bond lengths are in $\AA$.

A similar procedure allowed us to identify the most stable serine-Ca ${ }^{2+}$ adducts (see Figure 3) that could be obtained by direct attachment of the metal dication to one of its neutral conformers. It is worth noting, that as shown in a previous study, ${ }^{22}$ the global minimum $\mathbf{1}$ and its conformer $\mathbf{2}$, are characterized by a triply-coordinated $\mathrm{Ca}$ atom, bonded to the carbonyl oxygen of the acidic function, to the hydroxyl and to the amino groups as revealed by the atoms in molecules (AIM) analysis ${ }^{38-40}$ of their electron density. We have also considered the $\mathrm{Ca}^{2+}$ attachment to zwitterionic forms of serine, because although for the isolated system these forms are rather high in energy, different computational studies have shown that in the gas phase the interaction of an alkali-earth dication strongly stabilizes the zwitterionic forms of amino acids. In the particular case of glycine, the interaction with a zwitterionic form (Salt-bridge, SB) is found more favorable than with a neutral one (Charge-solvated, CS) for all the alkali-earth metals but Be. ${ }^{41}$ The energy gap between these forms is generally small. In addition, different theoretical studies have demonstrated that the interconversion barrier between complexes 
involving SB and CS forms can be barrierless. The process was found spontaneous ${ }^{42}$ for $\mathrm{Mg}^{2+}$ and it was shown that for $\mathrm{Ca}^{2+}$, the intramolecular proton transfer leading to the zwitterionic glycine occurred without any activation barrier. ${ }^{43}$ One may therefore reasonably consider the possibility of the presence of mixture of structures in aqueous solution of calcium chloride and amino acids, and that interconversion processes may potentially occur either in solution or during the electrospray process. The association of $\mathrm{Ca}^{2+}$ to the oxygen atoms of these zwitterionic species is particularly stabilizing, and indeed three of these forms, namely 3, 4 and $\mathbf{5}$ in Figure 3, are among the most stable serine- $\mathrm{Ca}^{2+}$ adducts. Our estimations indicate that whereas the energy gap between canonical and zwitterionic forms of serine is around $130 \mathrm{~kJ} \cdot \mathrm{mol}^{-1}$ or larger, the association to $\mathrm{Ca}^{2+}$ reduces de energy gap to about $25 \mathrm{~kJ} \cdot \mathrm{mol}^{-1}$ (see Table $\mathrm{S} 2$ of the Supporting Information). Similar findings have been reported in the literature for the case of glycine$\mathrm{Ca}^{2+}$ interactions. ${ }^{44}$ IRMPD studies have also demonstrated the presence of zwitterionic species for different systems. Dunbar and co-workers ${ }^{45}$ reported the IRMPD spectrum of divalent barium complexed with tryptophan and concluded that tryptophan is zwitterionic in this ion. Similarly, it was demonstrated that arginine, glutamine, proline, serine, and valine all adopt zwitterionic structures when complexed with divalent barium. ${ }^{46}$ The same conclusion could be drawn for $\mathrm{Sr}^{2+} /$ arginine system. In the particular case of Serine interacting with alkali metals, a mixture of different structures were observed in presence of $\mathrm{K}^{+}, \mathrm{Rb}^{+}$and $\mathrm{Cs}^{+}$, and the presence of a zwitterionic form was evidenced for the latter. ${ }^{47}$ Performing IRMPD studies would clearly indicate whether CS, SB or a mixture of both are actually generated under ESI conditions for the present system, provided it can be generated by ESI in an ion trap device. 


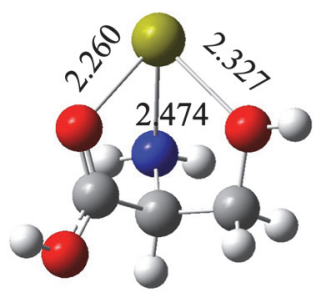

1

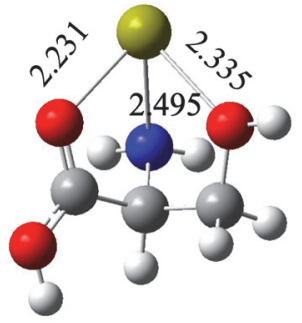

2

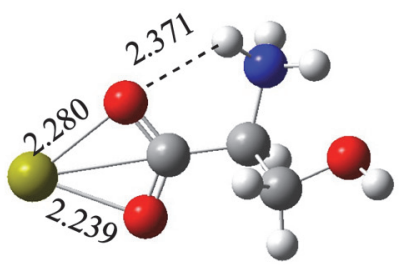

3

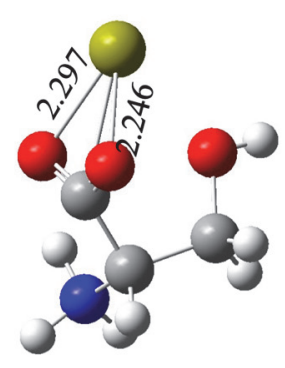

4

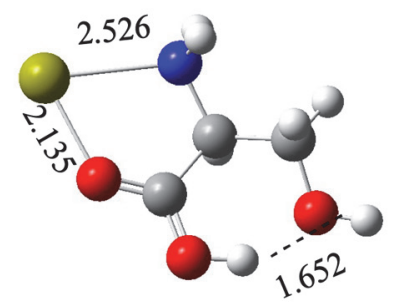

8

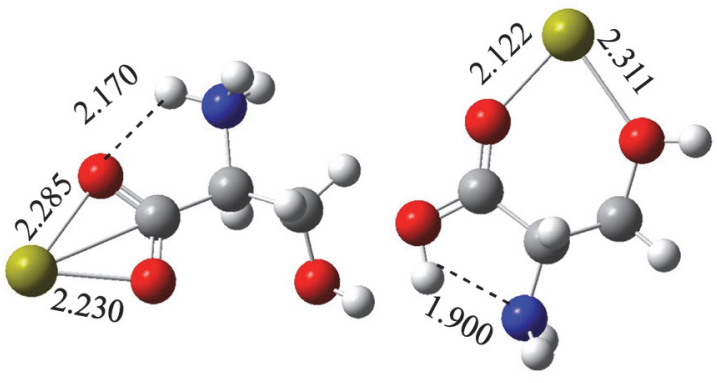

5
6

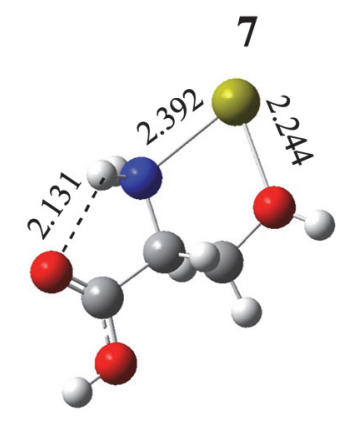

10

Figure 3. B3LYP/6-311+G(d,p) optimized geometries of the most stable conformers of serine- $\mathrm{Ca}^{2+}$ adducts. In structures $\mathbf{1}, \mathbf{2}$ and $7, \mathrm{Ca}$ appears tricoordinated. The intramolecular hydrogen bonds stabilizing these systems are also shown (dashed lines). Bond lengths are in $\AA$.

\section{Mechanisms for the unimolecular reactions of [serine-Ca] ${ }^{2+}$}

We will start our analysis of the possible reaction mechanisms leading to the products observed and summarized in Scheme 1, starting from the global minimum 1 of the $[\mathrm{Ca}(\mathrm{Ser})]^{2+}$ adduct.

\section{Coulomb explosions}


From all the possible mechanisms analyzed originating from the global minimum, the most favorable one, as it involves the lowest activation barriers, is the one associated to the coulomb explosions yielding $\mathrm{CaOH}^{+}$. The schematic potential energy profile corresponding to this process is displayed in Figure 4. The first step of the process is associated with a hydrogen transfer from the central $\mathrm{NH}_{2} \mathrm{CH}$ group to the $\mathrm{CH}_{2}$ group directly attached to it through the TS1-I1 transition state. This hydrogen transfer from the $\mathrm{NH}_{2} \mathrm{CH}$ group is accompanied by a dramatically reinforcement of its $\mathrm{C}-\mathrm{NH}_{2}$ bond, whereas the initial $\mathrm{Ca}-\mathrm{NH}_{2}$ weak bonding interaction ${ }^{22}$ disappears. At the same time, changing the $\mathrm{CH}_{2}$ group into a $\mathrm{CH}_{3}$ one also results in the cleavage of the initial $\mathrm{CH}_{2}-\mathrm{OH}$ linkage. Once the intermediate $\mathbf{I}$ is formed, the $\mathrm{O}-\mathrm{Ca}$ bond cleavage through the transition state TSI1-P1, results in the coulomb explosion yielding $\mathrm{CaOH}^{+}$, being the accompanying ion the $\mathrm{C} \alpha$ deprotonated form of alanine.

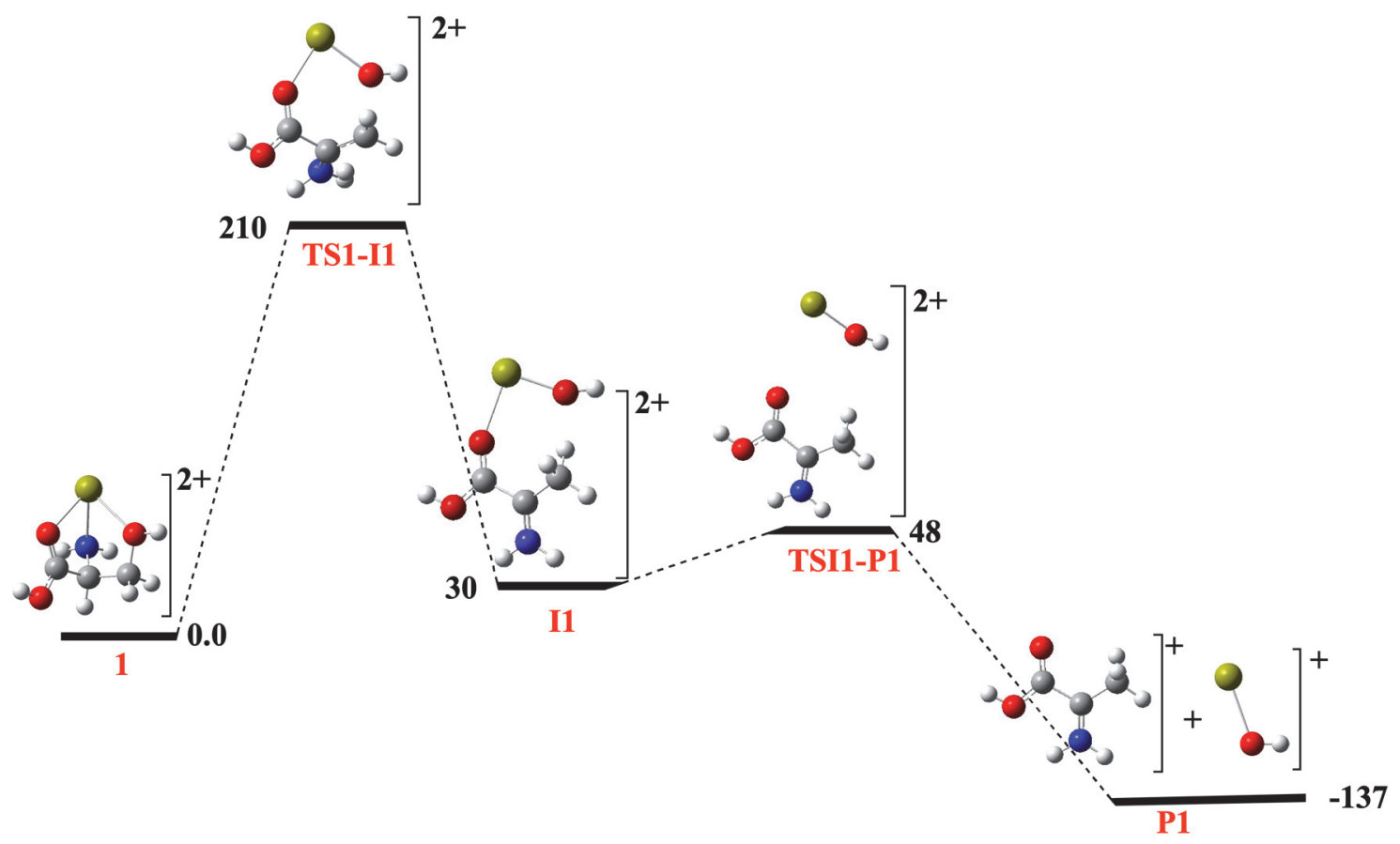

Figure 4. Enthalpy profile $(298.15 \mathrm{~K})$ for coulomb explosions of [serine-Ca] ${ }^{2+}$ yielding $\left[\mathrm{C}_{3}, \mathrm{H}_{6}, \mathrm{~N}, \mathrm{O}_{2}\right]^{+}+\mathrm{CaOH}^{+}$starting from the global minimum, 1. Relative enthalpies are in $\mathrm{kJ} \cdot \mathrm{mol}^{-1}$. 
However, other mechanisms leading to different monocations are possible. Figure 5 shows that the global minimum 1 easily connects with the local minimum 9 by the cleavage of the Ca- $\mathrm{NH}_{2}$ linkage. A $\mathrm{H}$ transfer from the $\mathrm{CH}-\mathrm{NH}_{2}$ group towards the near $\mathrm{COOH}$ group leads to the intermediate I17, which exhibits a $\mathrm{C}=\mathrm{NH}_{2}$ group. Subsequently, I17 structure undergoes a first rearrangement leading to I18, where Ca bridges between the two oxygen atoms of the $\mathrm{HOC}(\mathrm{H}) \mathrm{O}$ group just formed. A new H-transfer from the $\mathrm{NH}_{2}$ group towards the $\mathrm{CHOCaOH}$ group leads to $\mathbf{I 1 9}$ characterized by the presence of a very stable $\mathrm{CH}_{2} \mathrm{OCaOH}$ subunit, which will be one of the monocations formed in its coulomb explosion through the TSI19-P9 transition state.

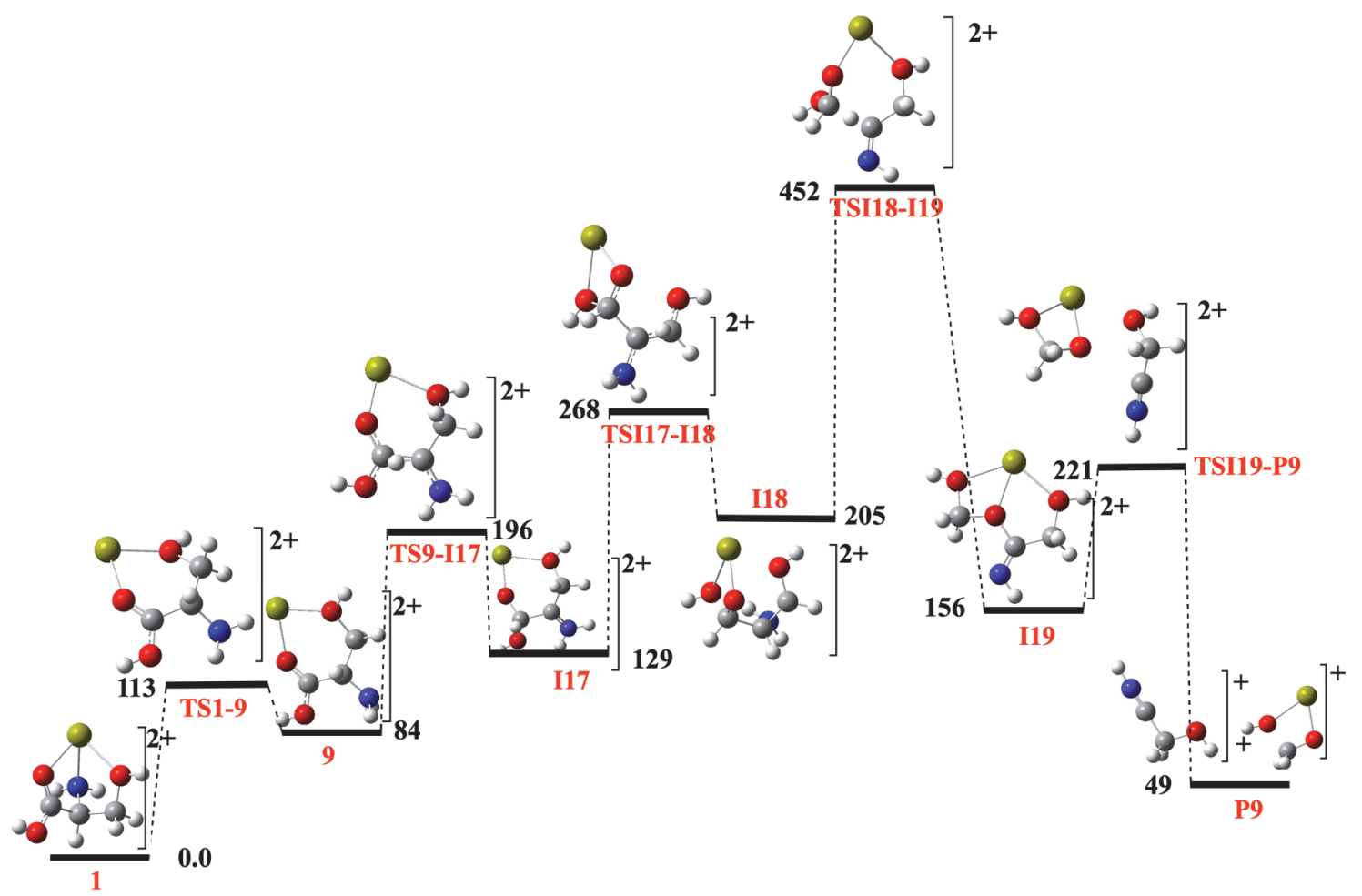

Figure 5. Enthalpy profile $(298.15 \mathrm{~K})$ for coulomb explosions of [serine-Ca] ${ }^{2+}$ yielding $\left[\mathrm{C}_{2}, \mathrm{H}_{4}, \mathrm{O}, \mathrm{N}\right]^{+}+\left[\mathrm{Ca}\left(\mathrm{C}, \mathrm{H}_{3}, \mathrm{O}_{2}\right)\right]^{+}$from the global minimum, 1. Relative enthalpies are in $\mathrm{kJ} \cdot \mathrm{mol}^{-1}$.

Hence, the monocation $\left[\mathrm{Ca}\left(\mathrm{C}, \mathrm{H}_{3}, \mathrm{O}_{2}\right)\right]^{+}$formed is the result of the bonding of $\mathrm{Ca}^{2+}$ to a molecule of formaldehyde and to a hydroxyl group. 


\section{Loss of water}

Dehydration is the prominent neutral loss observed experimentally. The possible mechanisms associated with the loss of water with origin at the global minimum 1 exhibit the energy profile shown in Figure 6. The first step corresponds to the hydrogen transfer from the $\mathrm{CH}_{2}$ group to the $\mathrm{OH}$ group attached to it. Such internal hydrogen transfer has been already suggested from the water loss observed for the $[\mathrm{Li}-\mathrm{Ser}]^{+}$complex. ${ }^{34}$ This process presently implies an activation barrier of $291 \mathrm{~kJ} \cdot \mathrm{mol}^{-1}$, with respect to adduct $\mathbf{1}$. The intermediate formed, I7, can undergo two processes. The first one would be the direct loss of water to yield the doubly-charged species P5 or alternatively undergo a second hydrogen transfer from the amino group to the $\mathrm{CH}$ group that remained after the first hydrogen transfer. This will lead to a rather stable intermediate, I8, in which the $\mathrm{Ca}$ atom is again tricoordinated. A further stabilization is achieved by a third $\mathrm{H}$ transfer from the $\mathrm{CH}$ to the $\mathrm{CH}_{2}$ group to yield intermediate $\mathbf{I 9}$, from which the loss of water will be much more favorable from the energetic viewpoint than the first water loss process mentioned above, yielding a dication, $\mathbf{P 4}$, in which $\mathrm{Ca}^{2+}$ is attached to the $\mathrm{NH}$ group of a deprotonated alanine molecule. 


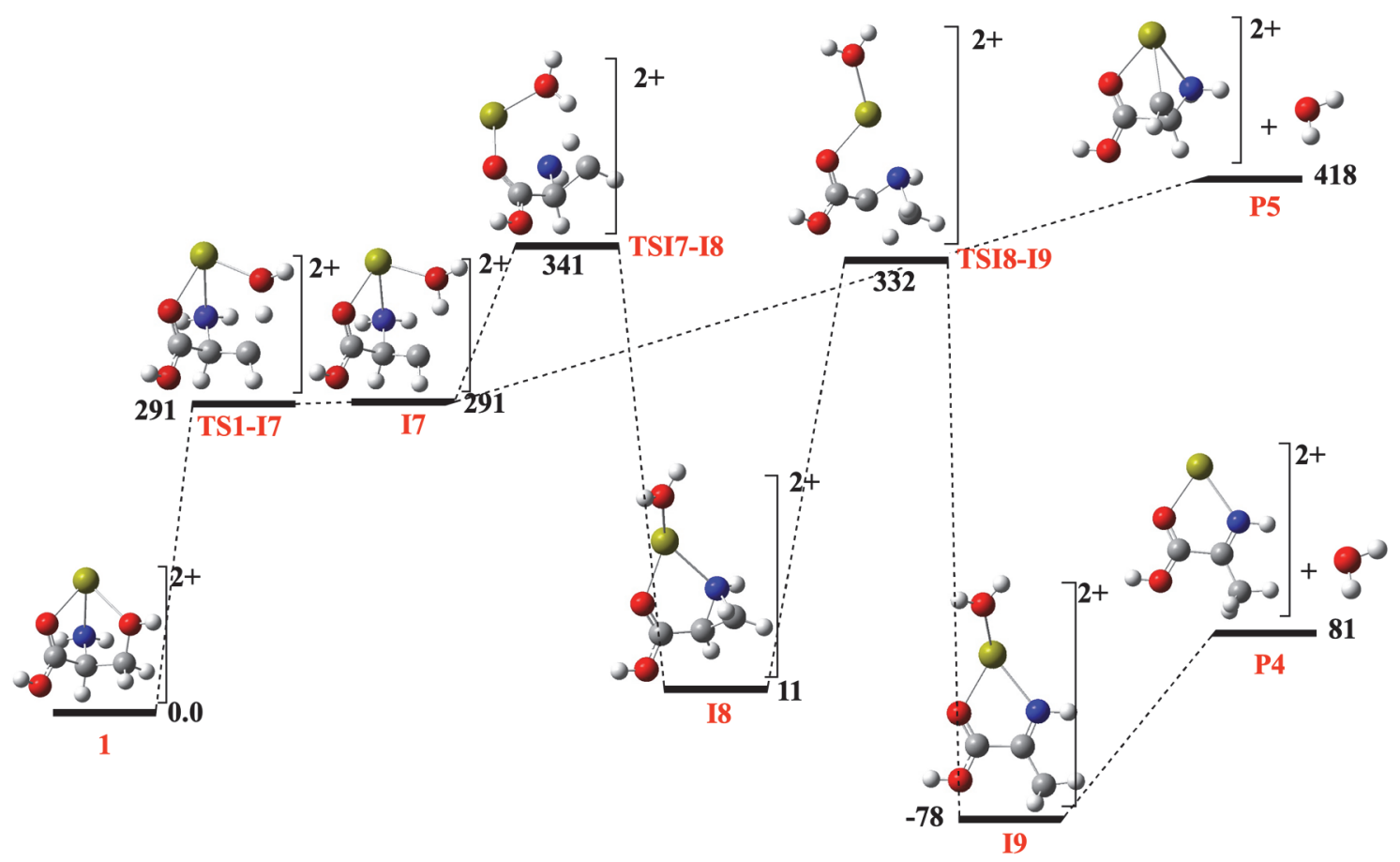

Figure 6. Enthalpy profile $(298.15 \mathrm{~K})$ for the loss of water from the $[\mathrm{Ca}(\mathrm{Ser})]^{2+}$ ion, originating from the global minimum, $\mathbf{1}$. Relative enthalpies are in $\mathrm{kJ} \cdot \mathrm{mol}^{-1}$.

\section{Loss of formaldehyde}

According to Scheme 1, the $[\mathrm{Ca}(\mathrm{Ser})]^{2+}$ ion can also lose formaldehyde rather than water. This reaction can also have its origin, as shown in Figure 7, from the global minimum, 1. 


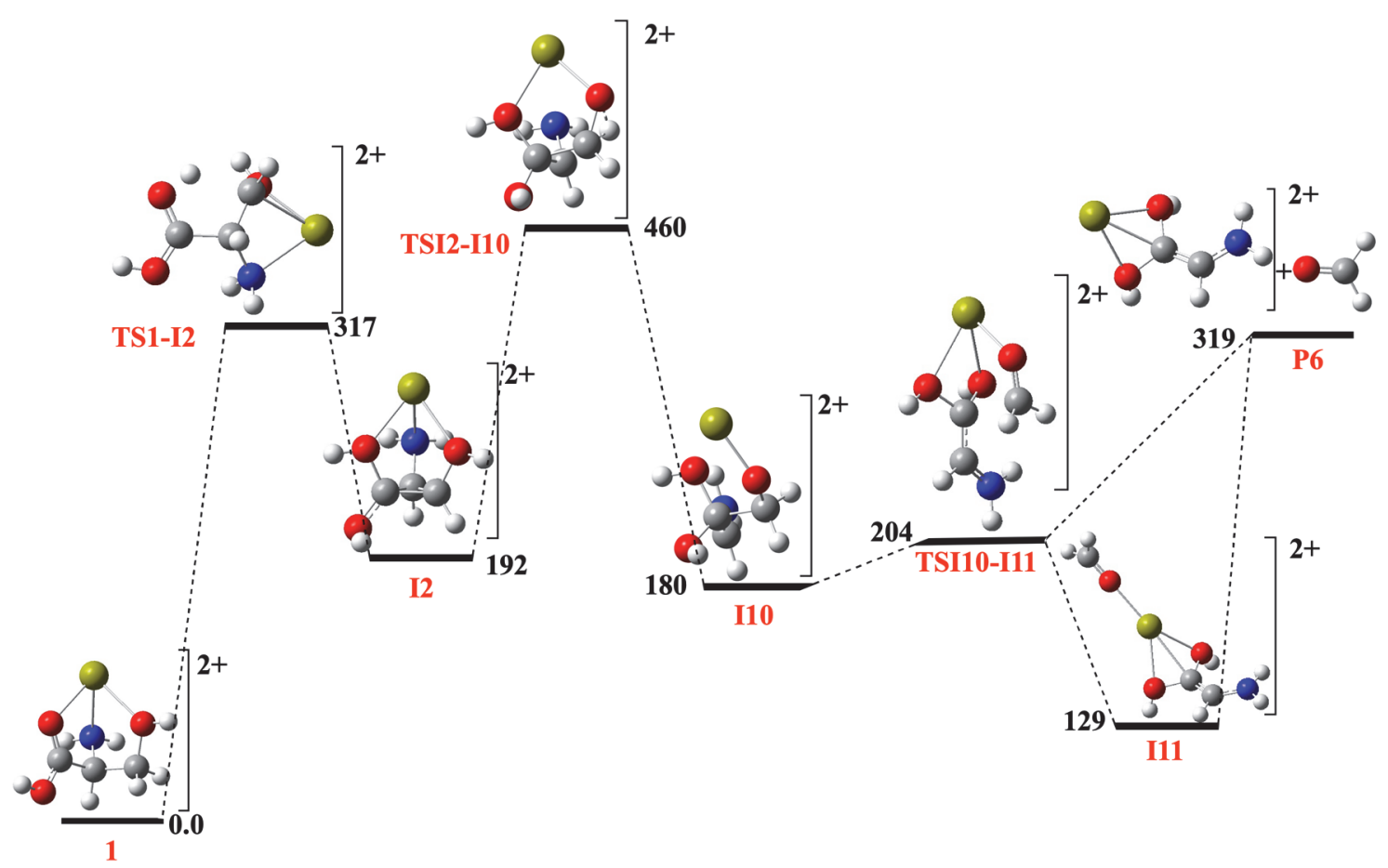

Figure 7. Enthalpy profile $(298.15 \mathrm{~K})$ for the loss of formaldehyde from the $[\mathrm{Ca}(\mathrm{Ser})]^{2+}$ ion, starting from the global minimum, 1. Relative enthalpies are in $\mathrm{kJ} \cdot \mathrm{mol}^{-1}$.

The most probable mechanism for the loss of $\mathrm{CH}_{2} \mathrm{O}$ from the global minimum involves the formation of the intermediate I2. From I2 a hydrogen transfer from the hydroxyl group to the vicinal $\mathrm{CH}$ yields the intermediate I10, slightly lower in energy. The subsequent interaction of $\mathrm{Ca}^{2+}$ with the two free $\mathrm{OH}$ groups leads to intermediate I11, which directly leads to the loss of formaldehyde. We have also indicated that the loss ofCH $\mathrm{H}_{2} \mathrm{O}$ can also occur from the transition state TSI10-I11, through a post-transition state dynamics similar to the one described before in the literature for formamide-Ca ${ }^{2+}$ reactions. ${ }^{48,49}$ Indeed, preliminary ADMP calculations show that in TSI10-11 the Ca$\mathrm{OCH}_{2}$ linkage breaks apart, so the loss of formaldehyde does not necessarily involve the transient formation of the more stable local minimum I11. The possibility of having other post-transition state dynamics in the different mechanisms included in this study should 
not be necessarily small, but a more detailed dynamical analysis is clearly beyond the scope of this paper.

\section{Alternative routes originating from other zwitterionic and non-zwitterionic minima}

We have also explored alternative mechanisms that can originate in other lowlying local minima, such as the zwitterionic complexes $\mathbf{3 , 4}$ and 5, or the non-zwitterionic species 6-9. As a suitable example, we present in Figure S4 of the Supporting Information the energy profiles corresponding to the loss of $\mathrm{CH}_{2} \mathrm{O}$ from complexes 4 (zwitterionic) and 6 (non-zwitterionic). It can be observed that the mechanism with origin at the zwitterionic form 4 clearly competes with the one starting from the global minimum (Figure 7), since all the activation barriers along the process are lower in energy as well as the final products $\mathbf{P 7}$ with respect to $\mathbf{P 6}$. This is also the case as far as the mechanism starting from adduct $\mathbf{6}$ is concerned, although the products $\mathbf{P 8}$ are much higher in energy, because the $\mathrm{HOCH}$ product is a high-lying isomer of formaldehyde. It should be noted however that the process leading to $\mathbf{P 8}$ is still exothermic and the $\mathrm{HOCH}$ molecule has enough internal energy to evolve to the $\mathrm{CH}_{2} \mathrm{O}$ global minimum, which lies $221 \mathrm{~kJ} \cdot \mathrm{mol}^{-1}$ lower in energy. It is worth noting that in all these products, the $\left[\mathrm{C}_{2}, \mathrm{H}_{5}, \mathrm{~N}, \mathrm{O}_{2}\right]$ moieties to which $\mathrm{Ca}^{2+}$ is attached are isobaric of glycine, so them can lead, as shown in Figure S5 of the Supporting Information, to $[\mathrm{Ca}(\mathrm{Gly})]^{2+}$ complexes either in their canonical or in their zwitterionic forms, ${ }^{44}$ in agreement with the behavior of the $\mathrm{Li}^{+}$-serine system, as reported by Ye and Armentrout. ${ }^{34}$

In Figure S6 of the supporting information, we present alternative coulomb explosion mechanisms to those shown above in Figure 5. The starting point would be again the global minimum $\mathbf{1}$, but evolving in this case to yield the local intermediate $\mathbf{I} 2$. From here, two alternative reactive pathways are open, one towards the intermediate $\mathbf{I 3}$ 
and a second one towards I4. In both cases, they evolve according to a coulomb explosion into $\left[\mathrm{Ca}\left(\mathrm{C}, \mathrm{H}_{3}, \mathrm{O}_{2}\right)\right]^{+}+\left[\mathrm{C}_{2}, \mathrm{H}_{4}, \mathrm{O}, \mathrm{N}\right]^{+}$monocations, but in conformations much less stable than the same species produced along the mechanism shown in Figure 5.

Figure S7 shows that starting from the same local minimum 9, another reaction pathway is opened leading to the loss of formaldehyde, though involving activation barriers that, although higher than those associated with the energy profile shown in Figure 7, may be still accessible and therefore, the contribution of this mechanism to the loss of formaldehyde should not be necessarily negligible.

\section{CONCLUDING REMARKS}

By means of electrospray ionization/mass spectrometry techniques and DFT calculations we have shown that $[\mathrm{Ca}(\mathrm{Ser})]^{2+}$ adduct dissociates in the gas phase either through coulomb explosion processes or through the loss of neutral fragments, mainly water and formaldehyde. Two different coulomb explosions were observed yielding either $\mathrm{CaOH}^{+}+\left[\mathrm{C}_{3}, \mathrm{H}_{6}, \mathrm{~N}_{2} \mathrm{O}_{2}\right]^{+}$or $\left[\mathrm{C}_{2}, \mathrm{H}_{4}, \mathrm{O}, \mathrm{N}\right]^{+}+\left[\mathrm{Ca}\left(\mathrm{C}, \mathrm{H}_{3}, \mathrm{O}_{2}\right)\right]^{+}$. However, according to our potential energy surfaces survey, the mechanisms involved and therefore the structures of the monocations produced, depend on the initial structure of the $[\mathrm{Ca}(\mathrm{Ser})]^{2+}$ adduct undergoing dissociation. They are different when the reactive process implies the global minimum or alternate low-lying isomers. A similar observation can be made as far as the losses of neutrals are concerned. Our theoretical survey of the energy profile allows us concluding that, although all the fragment ions can come from the global minimum, similar fragmentations involving both zwitterionic and non-zwitterionic low-lying conformers may compete, and should be considered to account for the observed reactivity. We have also found that in some specific cases post-transition state dynamics, similar to the ones described previously for formamide- 
$\mathrm{Ca}^{2+}$ reactions, may also play a role.

\section{ASSOCIATED CONTENT}

The Supporting Information is available free of charge on the ACS Publications website at DOI:

Calculated relative enthalpies, Boltzmann distribution and molecular graphs of serine conformers. Energy profiles of different unimolecular reactions of [serine-Ca] ${ }^{2+}$ adducts.

\section{AUTHOR INFORMATION}

\section{Corresponding Authors}

Email: mokhtar.lamsabhi@uam.es

Email: jeanyves.salpin@univ-evry.fr

\section{ACKNOWLEDGEMENTS}

This work was supported by the financial support received from the Ministerio de Economía, Industria y Competitividad (projects PGC2018-094644-B-C21 and CTQ2016-76061-P)). The Centro de Computación Científica of the UAM (CCC-UAM) are also acknowledged for their continued computational support.

\section{CONFLICT OF INTEREST}

The authors declare no conflict of interest.

\section{REFERENCES} 1979.

(1) Bowers, M. T. Gas Phase Ion Chemistry; Academci Press: New York,

(2) Adams, N. G.; Babcok, L. M. Advances in Gas-Phase Ion Chemistry; Elsevier Science: Hampton Hill, 2001; Vol. 4.

(3) Alcamí, M.; Mó, O.; Yáñez, M. Computational Chemistry. A useful (some times mandatory) tool in mass spectrometry studies. Mass Spectrom. Rev. 2001, 20, 195245. 
(4) Hase, W. L. Simulations of Gas-Phase Chemical Reactions: Applications to SN2 Nucleophilic Substitution. Science 1994, 266, 998-1002.

(5) Armentrout, P. B.; Baer, T. Gas-phase ion dynamics and chemistry. $J$. Phys. Chem. 1996, 100, 12866-12877.

(6) Michael L. Chabinyc; Stephen L. Craig; Colleen K. Regan; Brauman*, J. I. Gas-Phase Ionic Reactions: Dynamics and Mechanism of Nucleophilic Displacements. Science 1998, 1882-1886.

(7) Trujillo, C.; Lamsabhi, A. M.; Mó, O.; Yáñez, M. The importance of the oxidative character of doubly charged metal cations in binding neutral bases. [Urea-M] ${ }^{2+}$ and [thiourea-M] $]^{2+}(\mathrm{M}=\mathrm{Mg}, \mathrm{Ca}, \mathrm{Cu})$ complexes. Phys. Chem. Chem. Phys. 2008, 10, $3229-3235$.

(8) Corral, I.; Mó, O.; Yáñez, M.; Salpin, J.-Y.; Tortajada, J.; Radom, L. GasPhase Reactions between Urea and $\mathrm{Ca}^{2+}$ : The importance of Coulomb explosions. J. Phys. Chem. A 2004, 108, 10080-10088.

(9) Trujillo, C.; Mó, O.; Yáñez, M.; Salpin, J. Y.; Tortajada, J. Gas-Phase Reactions Between Thiourea and $\mathrm{Ca}^{2+}$. New evidences for the formation of $[\mathrm{Ca}(\mathrm{NH} 3)]^{2+}$ and other doubly-charged species. . ChemPhysChem 2007, 8, 1330.

(10) Trujillo, C.; Mó, O.; Yáñez, M.; Tortajada, J.; Salpin, J.-Y. Selenourea$\mathrm{Ca}^{2+}$ Reactions in Gas Phase. Similarities and dissimilarities with urea and thiourea. . $J$. Phys. Chem. B 2008, 112, 5479-5486.

(11) Jobst, K. J.; Terlouw, J. K.; Luider, T. M.; Burgers, P. C. On the interaction of peptides with calcium ions as studied by matrix-assisted laser desorption/ionization Fourier transform mass spectrometry: Towards peptide fishing using metal ion baits. Anal. Chim. Acta 2008, 627, 136-147.

(12) Dudev, T.; Lim, C. Competition among Metal Ions for Protein Binding Sites: Determinants of Metal Ion Selectivity in Proteins. Chem. Rev. 2014, 114, 538-556.

(13) Domínguez, D. C.; Guragain, M.; Patrauchan, M. Calcium binding proteins and calcium signaling in prokaryotes. Cell Calcium 2015, 57, 151-165.

(14) Tang, N.; Skibsted, L. H. Calcium Binding to Amino Acids and Small Glycine Peptides in Aqueous Solution: Toward Peptide Design for Better Calcium Bioavailability. J. Agric. Food Chem. 2016, 64, 4376-4389.

(15) Yang, J. J. Calciomics: Design and prediction of calcium binding proteins. Biophys. J. 2004, 86, 626A-626A.

(16) Zhou, Y. B.; Xue, S. H.; Yang, J. J. Calciomics: integrative studies of $\mathrm{Ca} 2+$-binding proteins and their interactomes in biological systems. Metallomics 2013, 5, $29-42$.

(17) Chernushevich, I. V.; Loboda, A. V.; Thomson, B. A. An introduction to quadrupole-time-of-flight mass spectrometry. J. Mass Spectrom. 2001, 36, 849-865.

(18) Corral, I.; Mó, O.; Yáñez, M.; Scott, A.; Radom, L. Interactions between Neutral Molecules and $\mathrm{Ca}^{2+}:$ An Assessment of Theoretical Procedures. J. Phys. Chem. A 2003, 107, 10456-10461.

(19) Becke, A. D. Density-functional exchange-energy approximation with correct asymptotic behavior. Phys. Rev. A. 1988, 38, 3098-3100.

(20) Lee, C.; Yang, W.; Parr, R. G. Development of the Colle-Salvetti correlation-energy formula into a functional of the electron density. Phys. Rev. B 1988, 37, 785-789.

(21) Frisch, M. J.; Trucks, G. W.; Schlegel, H. B.; Scuseria, G. E.; Robb, M. A.; Cheeseman, J. R.; Scalmani, G.; Barone, V.; Mennucci, B.; Petersson, G. A.et al. Gaussian09, Revision A.02; Gaussian09, Revision A.02 ed.; Gaussian, Inc.: Wallingford CT, 2009. 
(22) Corral, I.; Lamsabhi, A. M.; Mo, O.; Yanez, M. Infrared spectra of chargesolvated versus salt-bridge conformations of glycine-, serine-, and cysteine-Ca2+ complexes. Int. J. Quant. Chem. 2012, 112, 2126-2134.

(23) Suarez, D.; Rayon, V. M.; Diaz, N.; Valdes, H. Ab Initio Benchmark Calculations on $\mathrm{Ca}(\mathrm{II})$ Complexes and Assessment of Density Functional Theory Methodologies. J. Phys. Chem. A 2011, 115, 11331-11343.

(24) Schlegel, H. B.; Millam, J. M.; Iyengar, S. S.; Voth, G. A.; Daniels, A. D.; Scuseria, G. E.; Frisch, M. J. Ab initio molecular dynamics: Propagating the density matrix with Gaussian orbitals. J. Chem. Phys. 2001, 114, 9758-9763.

(25) Iyengar, S. S.; Schlegel, H. B.; Millam, J. M.; Voth, G. A.; Scuseria, G. E.; Frisch, M. J. Ab initio molecular dynamics: Propagating the density matrix with Gaussian orbitals. II. Generalizations based on mass-weighting, idempotency, energy conservation and choice of initial conditions. J. Chem. Phys. 2001, 115, 10291-10302.

(26) Beyer, M.; Williams, E. R.; Bondybey, V. E. Unimolecular reactions of dihydrated alkaline earth metal dications $\mathrm{M}^{2+}\left(\mathrm{H}_{2} \mathrm{O}\right)(2), \mathrm{M}=\mathrm{Be}, \mathrm{Mg}, \mathrm{Ca}, \mathrm{Sr}$, and Ba: Saltbridge mechanism in the proton-transfer reaction $\mathrm{M}^{2+}\left(\mathrm{H}_{2} \mathrm{O}\right)_{2-}>\mathrm{MOH}^{+}+\mathrm{H}_{3} \mathrm{O}^{+} . J . A m$. Chem. Soc. 1999, 121, 1565-1573.

(27) Corral, I.; Trujillo, C.; Salpin, J. Y.; Yáñez, M. $\mathrm{Ca}^{2+}$ reactivity in the gas phase. Bonding, catalytic effects and coulomb explosions. In Challenges and Advances in Computational Chemistry and Physics. Vol. 12 Kinetics and Dynamics: From Nanoto Bio-Scale; Paneth, P.-., Dybala-Defratyka, A., Eds.; Springer: London, 2010; Vol. 12.

(28) Carl, D. R.; Armentrout, P. B. Experimental Investigation of the Complete Inner Shell Hydration Energies of $\mathrm{Ca}^{2+}$ : Threshold Collision-Induced Dissociation of $\mathrm{Ca}^{2+}\left(\mathrm{H}_{2} \mathrm{O}\right)_{\mathrm{x}}$ Complexes (x=2-8). J. Phys. Chem. A 2012, 116, 3802-3815.

(29) Keller, B. O.; Sui, J.; Young, A. B.; Whittal, R. M. Interferences and contaminants encountered in modern mass spectrometry. Anal. Chim. Acta 2008, 627, 71-81.

(30) Hurtado, M.; Monte, M.; Lamsabhi, A. M.; Yáñez, M.; Mó, O.; Salpin, J.Y. Modeling Interactions between an Amino Acid and a Metal Dication: CysteineCalcium(II) Reactions in the Gas Phase. Chempluschem 2013, 78, 1124-1133.

(31) Ye, S. I.; Clark, A. A.; Armentrout, P. B. Experimental and theoretical investigation of alkali metal cation interactions with hydroxyl side-chain amino acids. $J$. Phys. Chem. B 2008, 112, 10291-10302.

(32) Bowman, V. N.; Heaton, A. L.; Armentrout, P. B. Metal Cation Dependence of Interactions with Amino Acids: Bond Energies of $\mathrm{Rb}^{+}$to Gly, Ser, Thr, and Pro. J. Phys. Chem. B 2010, 114, 4107-4114.

(33) Armentrout, P. B.; Chen, Y.; Rodgers, M. T. Metal Cation Dependence of Interactions with Amino Acids: Bond Energies of $\mathrm{Cs}^{+}$to Gly, Pro, Ser, Thr, and Cys. $J$. Phys. Chem. A 2012, 116, 3989-3999.

(34) Ye, S. I.; Armentrout, P. B. Experimental and theoretical investigation of the decomposition of lithiated hydroxyl side-chain amino acids. J. Phys. Chem. B 2008, 112, 10303-10313.

(35) Coates, R. A.; Boles, G. C.; McNary, C. P.; Berden, G.; Oomens, J.; Armentrout, P. B. $\mathrm{Zn}^{2+}$ and $\mathrm{Cd}^{2+}$ cationized serine complexes: infrared multiple photon dissociation spectroscopy and density functional theory investigations. Phys. Chem. Chem. Phys. 2016, 18, 22434-22445.

(36) Lamsabhi, A.; Mó, O.; Yáñez, M. Serine- $\mathrm{Ca}^{2+}$ versus serine- $\mathrm{Cu}^{2+}$ complexes - A theoretical perspective. Can. J. Chem. 2010, 88, 759-768.

(37) Bouchoux, G. Gas phase basicities of polyfunctional molecules. Part 3: Amino acids. Mass Spectrom. Rev. 2012, 31, 391-435. 
(38) Bader, R. F. W. Atoms in Molecules. A Quantum Theory; Clarendon Press: Oxford, 1990.

(39) Popelier, P. L. A. Atoms in Molecules: An Introduction; Prentice Hall: London, 1999.

(40) Matta, C. F.; Boyd, R. J. The Quantum Theory of Atoms in Molecules; Wiley-VCH: Weinheim, 2007.

(41) Strittmatter, E. F.; Lemoff, A. S.; Williams, E. R. Structure of cationized glycine, gly center dot $\mathrm{M}^{2+}(\mathrm{M}=\mathrm{Be}, \mathrm{Mg}, \mathrm{Ca}, \mathrm{Sr}, \mathrm{Ba})$, in the gas phase: Intrinsic effect of cation size on zwitterion stability. J. Phys. Chem. A 2000, 104, 9793-9796.

(42) Pulkkinen, S.; Noguera, M.; Rodriguez-Santiago, L.; Sodupe, M.; Bertran, J. Gas phase intramolecular proton transfer in cationized glycine and chlorine substituted derivatives (M-gly, $\mathrm{M}=\mathrm{Na}^{+}, \mathrm{Mg}^{2+}, \mathrm{Cu}^{+}, \mathrm{Ni}^{+}$, and $\mathrm{Cu}^{2+}$ ): Existence of zwitterionic structures? . Chem. Eur. J. 2000, 6, 4393-4399.

(43) Ai, H. Q.; Bu, Y. X.; Li, P. Intramolecular proton transfer induced by divalent alkali earth metal cation in the gas state. Int. J. Quant. Chem. 2003, 94, 205-214.

(44) Corral, I.; Mó, O.; Yáñez, M.; Salpin, J. Y.; Tortajada, J.; Moran, D.; Radom, L. An experimental and theoretical investigation of gas-phase reactions of $\mathrm{Ca}^{2+}$ with glycine. Chem. Eur. J 2006, 12, 6787-6796.

(45) Dunbar, R. C.; Polfer, N. C.; Oomens, J. Gas-phase zwitterion stabilization by a metal dication. J. Am. Chem. Soc. 2007, 129, 14562-14563.

(46) Bush, M. F.; Oomens, J.; Saykally, R. J.; Williams, E. R. Effects of alkaline earth metal ion complexation on amino acid zwitterion stability: Results from infrared action spectroscopy. J. Am. Chem. Soc. 2008, 130, 6463-6471.

(47) Armentrout, P. B.; Rodgers, M. T.; Oomens, J.; Steill, J. D. Infrared multiphoton dissociation spectroscopy of cationized serine: Effects of alkali-metal cation size on gas-phase conformation. J. Phys. Chem. A 2008, 112, 2248-2257.

(48) Martín-Sómer, A.; Yáñez, M.; Hase, W. L.; Gaigeot, M.-P.; Spezia, R. Post Transition State Dynamics in Gas Phase Reactivity: The Importance of Bifurcations and Rotational Activation. J. Chem. Theor. Comput. 2016, 12, 974-982

(49) Martín-Sómer, A.; Spezia, R.; Yáñez, M. Gas-phase reactivity of $\mathrm{Ca}$ (formamide) ${ }^{2+}$ complex: an example of different dynamical behaviours. Phil. Trans. $R$. Soc. A 2017, 375, 20160196. 